\title{
Temporomandibular disorders and parafunctional oral habits: An anamnestic study
}

\author{
Melissa de Oliveira Melchior', Marcelo Oliveira Mazzetto², Cláudia Maria de Felício³
}

Objective: To assess the frequency and severity of the signs and symptoms of temporomandibular disorders (TMD), the frequency of parafunctional oral habits and the correlation between the variables by means of the patients' perception regarding their problem.

Methods: One hundred patients diagnosed with TMD, through a clinical examination of their masticatory system, answered the questions of a previously published protocol concerning the signs and symptoms most frequently reported in the literature.

Results: According to the results from the non parametric statistical analysis, the frequency for the following signs and symptoms was significant: Fatigue and muscle pain, joint sounds, tinnitus, ear fullness, headache, chewing impairment and difficulty to yawn $(\mathrm{p}<0.01)$ and otalgia $(\mathrm{p}<0.05)$. As to the parafunctional oral habits, there was a significant presence of teeth clenching during the day and night $(\mathrm{p}<0.01)$ and teeth grinding at night $(\mathrm{p}<0.05)$. The variable correlation analysis showed that there was a positive correlation between symptom frequency and severity; age was correlated with the presence of otalgia, cervical pain and teeth sensitivity, besides being correlated with muscle and joint pain severity. Habit frequency was negatively correlated with age. TMD duration was also positively correlated with the symptoms of tinnitus, ear fullness, muscle and joint pain.

Conclusion: The study results showed that the anamnestic assessment using ProDTMMulti can predict the severity of the TMD case.

Keywords: Temporomandibular Joint disorders. Signs and symptoms. Habits.

${ }^{1}$ Speech Pathologist, School of Dentistry of Ribeirão Preto - USP;

${ }^{2}$ Head Professor, Department of Restorative Dentistry, School of Dentistry of Ribeirão Preto - USP;

${ }^{3}$ Professor, Department of Ophthalmology, Otolaryngology and Surgery of Neck and Head, Speech Therapy department, School of Medicine of Ribeirão Preto - USP.
How to cite this article: Melchior MO, Mazzetto MO, Felício CM. Temporomandibular disorders and parafunctional oral habits: An anamnestic study. Dental Press J Orthod. 2012 Mar-Apr;17(2):83-9.

Submitted: August 27, 2008 - Revised and accepted: December 30, 2009

" The authors report no commercial, proprietary, or financial interest in the products or companies described in this article.

Contact address: Melissa de Oliveira Melchior

Av. do Café, s/n. - CEP: 14.040-904 - Ribeirão Preto/SP - Brazil

E-mail:mmelchior@forp.usp.br. 


\section{INTRODUCTION}

Temporomandibular disorders (TMD) have been recognized as a common condition of orofacial pain and its clinical manifestation includes a set of signs and symptoms. Among them, pain almost always takes a prominent role, which can impair the functioning of the stomatognathic system and the quality of life. ${ }^{7,21,36}$ TMD diagnosis is mainly clinical and maybe supplemented by images. ${ }^{43}$ But often what drives the patient to seek treatment is the sign and symptom perception.

Pain in the masticatory muscles and temporomandibular joint (TMJ), difficulty in jaw movement, joint sounds, difficulties related to stomatognathic functions and otologic symptoms are commonly reported by affected subjects. ${ }^{7,26}$

It is believed that habits can act as an important etiologic factor of TMD, as they lead to a traumatic dental occlusion that may affect the teeth and the masticatory muscles and temporomandibular joints, causing the disruption of the functional balance stomatognathic system, or worsening the already installed TMD. ${ }^{16,19,30,31,32}$ Thus, some studies have reported that the amount, frequency, intensity and duration of habits can determine the severity of signs and symptoms of TMD, as they relate to fatigue and muscle pain, in addition to joint compression. ${ }^{13,15,30}$

Onychophagy, gum chewing, biting or clenching objects between the teeth, constantly biting cheeks and lips, resting the jaws on the hands, clenching and/or bruxism, among other habits, are commonly reported by TMD patients. ${ }^{16,31,32}$

Studies have shown that anamnestic investigation is valid for the identification of $\mathrm{TMD}^{14}$ and it may also give positive correlations with clinical findings. ${ }^{14,28}$ Previously, our team standardized the patient records about signs and symptoms of TMD, which allowed the definition of the frequency and severity of the condition, as well as verification of the treatment effects. ${ }^{13}$

The objective of this study was to determine the frequency and severity of TMD signs and symptoms and the frequency of deleterious oral habits present in a sample by means of a questionnaire to assess self-perception of symptoms, and to examine possible correlations between the variables: Age of the subjects, severity of symptoms, frequency of signs and symptoms, number of habits, duration of TMD.

\section{MATERIAL AND METHODS}

The project was approved by the Ethics Committee of the School of Dentistry of Ribeirão Preto, University of São Paulo (process number 2001.1.266.58.5). All subjects were informed about the objectives of the study and signed an informed consent.

One hundred female subjects, with ages ranging from 11 to 74 years (mean 33.49 years) participated in this study. They were choose because they were the majority seeking for treatment on the waiting list.

\section{Procedures}

The patients were called for treatment of TMD, in a waiting list of the university.

The inclusion criterion was to present classification of muscular and/or articular TMD according to Research Diagnostic Criteria for Temporomandibular Disorders (RDC/TMD), ${ }^{9}$ applied by a trained examiner. Therefore, the subjects should have TMD signs and symptoms and the presence of pain in the masticatory muscles and/or the temporomandibular joint, limitation or deviation of mandibular movements, TMJ sounds and static and/or unusual dynamic occlusal relationship. ${ }^{7}$

Exclusion criteria were patients with central or peripheral neurological disorders, or who had suffered trauma or tumors in the head and neck.

The subjects were examined while seated in a dental chair with adequate lighting. To check the conditions, morphofunctional evaluation was made of the static and dynamic occlusion. To identify the regions of pain, it was performed palpation of the masseter, temporal, suprahyoid, medial and lateral pterygoid, the insertion of the temporalis muscles (intraoral) and TMJs. The region of TMJ was also palpated during mandibular motion for the identification of joint noises, which were confirmed by auscultation. Clinical examination was carried out based on the criteria required by the protocol RDC/TMD. ${ }^{9}$

To obtain data on the perception of the subjects for signs and symptoms of TMD, it was used the "Protocol for Multidisciplinary Centers for the Determination of Signs and Symptoms of TMD 
(ProDTMMulti), which contains 2 parts. Patients answered questions of the first part of the protocol, which admitted only affirmative or negative answers about the signs and symptoms and deleterious oral habits. In the second part, they were asked to express the severity of signs or symptoms questioned according to the situation, that is, at waking up, chewing, speaking and at rest, using a 11-point numerical scale, with the help of a printed graduated scale: Zero was considered complete absence of symptoms or signs, and 10 the greatest severity possible. The severity scale was composed by the sum of the scores assigned to each sign and/ or symptoms in the four questioned situations. The procedures were performed individually and patients' responses to each item were marked by the same examiner in the protocol.

To obtain data on deleterious oral habits, subjects were asked about the presence of the following behaviors: Clenching during day and/or nighttime, grinding teeth during day and/or nighttime, chewing gum, biting objects and nails, and some other habit that had not been questioned. The subjects should answer each question with affirmative or negative answers.

\section{Analysis of data}

The data were described in terms of frequencies and analyzed using nonparametric statistics. The binomial test was employed to analyze the presence of significance in relation to the absence of signs and symptoms of deleterious oral habits and Spearman correlation analysis for the correlation between the variables: Age of the subjects with the severity of symptoms and the number of habits; severity of symptoms with a duration of TMD, with the frequency of signs and symptoms and the number of deleterious oral habits.

\section{RESULTS}

In this study, 65 out of 100 subjects had 21 to 40 years, 11 patients with less than 21 years and 24 subjects with more than 40 years. The time between the first symptoms reported by patients and the first assessment date in FORP/USP ranged from 1 to 23 years.

In this sample, there was significant presence of signs and symptoms of muscle pain, joint noise, fatigue, tinnitus, ear fullness, headache, difficulty opening the mouth, chewing and yawning impairment $(\mathrm{p}<0.01)$ and otalgia $(\mathrm{p}<0.05)$.

A significant number of patients did not related difficulty to close the mouth. The frequencies and levels of significance are shown in Table 1.

\section{Frequency of deleterious oral habits}

Only four sample subjects reported no deleterious oral habits. Thirty-five reported 1 to 3 habits, while 61 subjects reported having 4 to 8 habits. There were reports of significant presence from diurnal and nocturnal clenching $(\mathrm{p}<0.01)$ and grinding of teeth at night $(\mathrm{p}<0.05)$. The other deleterious habits did not show significant presence in the sample or their absence were significant (Table 2).

\section{Correlations}

The age of subjects was positively correlated to the severity of muscle pain $(\mathrm{r}=0.26, \mathrm{p}<0.01)$, TMJ pain $(r=0.28, p<0.01)$, ear ache $(r=0.32, p<0.01)$, neck pain $(\mathrm{r}=0.27, \mathrm{p}<0.01)$ and tooth sensitivity $(\mathrm{r}=0.28, \mathrm{p}<0.01)$. Also the length of the TMD was related to the severity of muscle pain $(r=0.37$, $\mathrm{p}<0.01)$, TMJ pain $(\mathrm{r}=0.28, \mathrm{p}<0.01)$, tinnitus $(\mathrm{r}=$ $0.21, \mathrm{p}<0.05)$ and ear fullness $(\mathrm{r}=0.21, \mathrm{p}<0.05)$.

Table 1 - Frequency of TMD symptoms and noise signs present in the sample.

\begin{tabular}{ccc}
\hline \multicolumn{2}{c}{ Binomial Test $(\mathbf{n}=\mathbf{1 0 0})$} & \\
\hline Signs and symptoms & Presence & Absence \\
\hline Muscle pain & $93^{\star \star}$ & 07 \\
Joint noise & $91^{\star \star}$ & 09 \\
Fatigue & $84^{\star \star}$ & 16 \\
Tinnitus & $81^{\star \star}$ & 19 \\
Ear fullness & $76^{\star \star}$ & 24 \\
Headache & $76^{\star \star}$ & 24 \\
Difficulty to open mouth & $73^{\star \star}$ & 27 \\
Chewing impairment & $73^{\star \star}$ & 27 \\
Yawning impairment & $67^{\star \star}$ & 33 \\
Ear ache & $62^{\star}$ & 38 \\
Difficulty to close the mouth & 38 & $62^{\star}$ \\
\hline
\end{tabular}

Binomial test: ${ }^{\star} 0.05$ level of significance; ${ }^{* \star} 0.01$ level of significance. 
There were positive and significant correlation between the number of symptoms and the severity of each TMD sign and/or symptoms ( $<<0.001)$. Sample distribution according to the severity of each sign and/or symptom, and the Spearman correlation coefficients are shown in Table 3.

The frequency of habits was negatively correlated with age of the subjects $(r=0.24, \mathrm{p}<0.05)$. There was no significant correlation between the number of deleterious oral habits and TMD severity ( $p>0.05)$.

\section{DISCUSSION}

The time between the first symptoms reported by patients and the date the first assessment in FORP/ USP ranged from 1 to 23 years, indicating that the treatment usually begins at the stage of chronic or recurrent disorder. The duration of symptoms is far beyond the time established by the International Association for the Study of Pain (IASP) in $1994^{23}$ to describe a clinical state of chronic pain, which would be at least 6 months history of pain, and more an attempt to unsuccessful treatment.

By the variety of symptoms present in TMD, it is common that people affected by the problem look different professionals and specialists such as neurologists, otorhinolaryngologists and general practitioners before arriving and/or referred to a specialist service in DTM, ${ }^{11}$ which ends up making treatment to be initiated already in a chronic stage of the disorder. This suggests the existence of difficulties in reaching the correct diagnosis and, consequently, to indicate the most appropriate treatment for each case, which in turn may be due to a lack of consensus on the methods of diagnosis, lack of preparation of professionals to recognize dysfunction and difficulty in identifying the etiology. ${ }^{19,46}$ In addition, there is the fact that many patients seek treatment only when the disorder is recognized by them due to the increased symptomatology.

Table 2 - Frequency of deleterious oral habits in the studied sample.

\begin{tabular}{|c|c|c|}
\hline \multicolumn{3}{|c|}{ Binomial test $(n=100)$} \\
\hline Habits & Presence & Absence \\
\hline Daytime clenching & $73^{\star \star}$ & 27 \\
\hline Nighttime clenching & $66^{\star \star}$ & 34 \\
\hline Teeth grinding (nocturnal) & $61^{\star}$ & 39 \\
\hline Gum chewing & 50 & 50 \\
\hline Biting objects & 38 & $62^{\star}$ \\
\hline Onychophagia & 33 & $67^{\star \star}$ \\
\hline Teeth grinding (daytime) & 23 & $77^{\star \star}$ \\
\hline Other habits (sum) & 44 & 56 \\
\hline
\end{tabular}

Binomial test: ${ }^{\star} 0.05$ level of significance, ${ }^{\star \star} 0.01$ level of significance.

Table 3 - Distribution of absolute frequencies of the severity of the TMD signs and symptoms and Spearman correlation coefficients ( $r$ ) between the number of signs and symptoms and the severity of each one.

Severity of TMD Signs and Symptoms

\begin{tabular}{|c|c|c|c|c|c|c|}
\hline Symptoms & Grade 0 & $\begin{array}{c}\text { Grade } 1 \\
(1-10)\end{array}$ & $\begin{array}{l}\text { Grade } 2 \\
(11-20)\end{array}$ & $\begin{array}{l}\text { Grade } 3 \\
(21-30)\end{array}$ & $\begin{array}{l}\text { Grade } 4 \\
(31-40)\end{array}$ & $r$ \\
\hline Muscular pain & 03 & 22 & 33 & 24 & 18 & $0.45^{\star \star \star}$ \\
\hline TMJ pain & 08 & 22 & 32 & 21 & 17 & $0.53^{\star \star \star}$ \\
\hline Neck pain & 12 & 25 & 22 & 22 & 19 & $0.48^{\star \star \star}$ \\
\hline Ear ache & 32 & 33 & 19 & 07 & 09 & $0.50^{\star \star \star}$ \\
\hline Tinnitus & 27 & 37 & 18 & 12 & 06 & $0.38^{\star \star \star}$ \\
\hline Ear fullness & 22 & 37 & 22 & 11 & 08 & $0.29^{\star \star}$ \\
\hline Tooth sensitiveness & 20 & 34 & 14 & 21 & 11 & $0.33^{\star \star}$ \\
\hline TMJ noise & 10 & 25 & 36 & 16 & 13 & $0.53^{\star \star \star}$ \\
\hline
\end{tabular}

${ }^{\star \star} 0.01$ level of significance; ${ }^{\star \star \star} 0.001$ level of significance. 
In this study, subjects were selected based on $\mathrm{RDC} / \mathrm{TMD},{ }^{9}$ which has been widely adopted as a method of classifying DTM..$^{8,9,42,45}$ However, this is not the most appropriate method to understand the level of severity. Thus, we used the ProDTMMulti previously constructed to standardize the records about the signs and symptoms of patients in multidisciplinary clinics, and to identify what are the signs and symptoms that affect the patient and their severity, and what are the most critical conditions on a daily basis. ${ }^{13}$

The significant presence of several signs and symptoms investigated in this study confirms the features found in other populations with TMD, ${ }^{6,13,19,46}$ as well as the presence of significant reports of day and nighttime clenching and grinding of teeth at night. ${ }^{30,31,32}$ Although these are expected results, because it is a preselected population with TMD, it was interesting to note the patient's ability to affirm or deny what they felt, which complemented the clinical assessments effectively. So this is confirmed as a useful method to identify a dysfunction, ${ }^{13}$ which can be easily applied by different health professionals, as is their proposal.

Among the deleterious oral habits, bruxism has been considered an important maintenance factor of TMD. ${ }^{15,18,31,32,41}$ The significant presence of diurnal and nocturnal clenching and teeth grinding (nocturnal) in this study, but not other habits, suggests the importance of bruxism on the progression and/or on non-remission of the disorder, being the clenching a more important risk factor than grinding. ${ }^{6,15,30,31,40,41}$ And while Choi and Choung Moon ${ }^{6}$ have reported that bruxism cannot be a direct risk factor for TMD, there are reports showing that clenching was more often associated with TMJ symptoms and clinically relevant to the occurrence of the same, increasing the risk of manifestation of TMJ pain and noise and losses in the mouth opening. ${ }^{17,22,24,29,44}$

Therefore, a likely association between bruxism and TMD signs/symptoms supports the theory that repetitive loads on the masticatory system can cause functional disorders. ${ }^{3}$

Regarding the positive correlation observed between age and severity of signs and symptoms, it should be considered that only 24 sample subjects had more than 40 years. Therefore, it did not necessarily mean that the more advanced the age of the subject, the greater the severity of the pain present in the TMJ and muscles. As recognized in the literature, the age group most affected by TMD is the

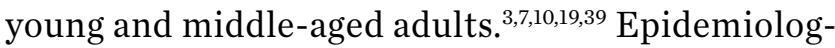
ical studies revealed that, unlike many other musculoskeletal conditions, the TMD has no increase in incidence or prevalence with increasing age. ${ }^{19,25}$

The higher frequency of TMD between 21 and 40 years of age over the older age groups was considered suggestive of the influence of psychological tensions that are inherent to the time of greatest productivity of these individuals, over the painful symptoms of TMD. ${ }^{5}$

The duration of the TMD was correlated with muscle pain, TMJ pain and tinnitus and ear fullness. In the presence of pain and other symptoms, many compensations in the stomatognathic system can occur to allow that chewing, swallowing and speech might be carried out within the limit of efficiency and comfort. However, the actual compensation may have negative medium and long term effects, causing more imbalance and cumulative losses, because such compensations are not necessarily healthy ${ }^{2,47}$. Moreover, the process of chronic pain and the indiscriminate use of analgesics without medical control, as often occurs among patients with TMD, may worsen the case..$^{20,37}$

Significant relationships have been found between the otologic symptoms and other TMD signs and symptoms, ${ }^{4,38}$ as well as the functional difficulties of the stomatognathic system. ${ }^{12}$

In the present study, we observed that the perception of severity of ear pain was correlated with the age of subjects. Meanwhile, the consciousness of severity of tinnitus and ear fullness symptoms was correlated with the duration of TMD, suggesting their association with TMD and not agerelated ear problems. Earlier studies hypothesized that such symptoms may be caused by anatomical and functional relationships between the TMJ, the muscles innervated by the trigeminal nerve and the structures of the ear. . $^{1,27,33}$

The significant correlation between the frequency and severity of signs and symptoms are an indication that the larger the number of signs and 
symptoms, the greater the severity perceived by the patient. And, although several authors suggest that the habits accumulation can lead to worsening or contribute to no remission of the present scenario, and deleterious oral habits are among the TMD etiological factors, ${ }^{15,19,30,31,32}$ the frequency of habits was not correlated to the frequency or severity of signs and symptoms, according to data analyzed from ProDTMMulti ${ }^{13}$ in the current population. In a previous study, it was suggested that, in relation to bruxism, there is an effect of habit in time ${ }^{30}$. Probably the intensity and duration are more important than the number of habits. However, according to the limits imposed by the instrument used in this study, such measurement was not possible.

There were no significant presence of gum chewing habits and onychophagia in our sample, as well as the correlation between habits and age was negative. Research conducted with student populations pointed that gum chewing and onychophagia are the main habits and classified them as juvenile habits. ${ }^{16,29}$

The nature of this investigation allowed us to know about TMD symptoms in the light of who suffers it, revealing the possibility of using the protocol ProDTMMulti ${ }^{13}$ as a tool for identification of a potential framework for TMD. Moreover, the possibility to register information about the awareness and consciousness of the population studied in relation to clenching and/or grinding of teeth facilitates the treatment plan, starting at the point of self consciousness to achieve some changes in behavior. ${ }^{11}$

\section{CONCLUSION}

Considering the limitations of an anamnestic study and based on the ProDTMMulti data, we conclude that the amount of signs and symptoms and their duration, may be predictive of the TMD severity, according to patients' own perceptions. Symptoms of day and nighttime clenching and nighttime grinding of teeth were significant, revealing the awareness and consciousness of the population studied in relation to them. And yet, the otologic symptoms of tinnitus and ear fullness were correlated with the time of dysfunction and not with age. However, such findings were based mainly on patients answers. A clinical investigation should be performed to confirm and generalize these findings. Furthermore, this study does not provide causal relationship, but only an association between the variables. Future work should be carried out to elucidate each topic individually. 


\section{REFERENCES}

1. Arlen H. The otomandibular syndrome. In: Gelb H. Clinical management of head, neck and TMJ pain and dysfunction: a multi-disciplinary approach to diagnostic and treatment. Philadelphia: Saunders; 1985. p. 181-95.

2. Bianchini EMG. Articulação temporomandibular: implicações, limitações e possibilidades fonoaudiológicas. Carapicuíba: Pró-Fono; 2000

3. Bove SRK, Guimarães AS, Smith RL. Caracterização dos pacientes de um ambulatório de disfunção temporomandibular e dor orofacial. Rev Latino-Am Enfermagem. 2005;13(5):686-91.

4. Camparis CM, Formigoni G, Teixeira MJ, Siqueira JT. Clinical evaluation of tinnitus in patients with sleep bruxism: prevalence and characteristics. J Oral Rehabil. 2005;32(11) 808-14.

5. Cauás M, Alves IF, Tenório K, HC Filho JB, Guerra CMF. Incidences of parafunctional habits and posture in with patients craniomandibular dysfunction. Rev Cir Traumatol Buco-maxilo-fac. 2004;4(2):117-24.

6. Choi YS, Choung PH, Moon HS, Kim SG. Temporomandibular disorders in 19-year-old Korean men. J Oral Maxillofac Surg. 2002;60(7):797-803.

7. Dworkin SF, Huggins KH, Leresche L, Van Korff M, Howard J, Truelove E, Sommers E. Epidemiology of signs and symptoms in temporomandibular disorders: clinical signs in cases and controls. J Am Dent Assoc. 1990;120(3):273-81

8. Dworkin SF, Huggins KH, Wilson L, Mancl L, Turner J, Massoth D, et al. A Randomized clinical trial using Research Diagnostic Criteria for temporomandibular disorders-Axis II to target clinic cases for tailored self-care TMD treatment program. J Orofac Pain. 2002;16(1):48-63.

9. Dworkin SF, Leresche L. Research diagnostic criteria for temporomandibular disorders: Review, criteria, examinations and specifications, critique. J Craniomandib Disord Facial Oral Pain. 1992;6(4):301-55.

10. Esposito CJ, Panucci PJ, Farman AG. Associations in 425 patients having temporomandibular disorders. J Ky Med Assoc. 2000;98(5):213-5.

11. Felício CM. Fonoaudiologia nas desordens temporomandibulares: uma ação educativa-terapêutica. São Paulo: Pancast; 1994. 179 p.

12. Felício CM, Faria TG, Silva MAMR, Aquino AMCM, Junqueira CA. Desordem temporomandibular: relações entre sintomas otológicos e orofaciais. Rev Bras Otorrinolaringol. 2004;70(6):786-93.

13. Felício CM, Mazzetto MO, Silva MAMR, Bataglion C, Hotta THA. Preliminary protocol for multi-professional centers for determination of signs and symptoms of temporomandibular disorders. Cranio. 2006;24(4):258-64.

14. Fonseca DM, Bonfante G, Valle AL, Freitas SFT. Diagnóstico pela anamnese da disfunção temporomandibular. RGO: Rev Gaúcha Odontol. 1994;42(1):23-8.

15. Fujita Y, Motegi E, Nomura M, Kawamura S, Yamaguchi D, Yamaguchi H. Oral habits of temporomandibular disorder patient with malocclusion. Bull Tokyo Dent Coll. 2003;44(4):201-7.

16. Gavish A, Halachmi M, Winocur E, Gazit E. Oral habits and their association with signs and symptoms of temporomandibular disorders in adolescent girls. J Oral Rehabil. 2000;27(1):22-32

17. Gesch D, Benhardt O, Alte D, Schwahn C, Kocher I, John U, et al. Prevalence of signs and symptoms of temporomandibular disorders in an urban and rural German population-based study of health in Pomerania. Quintessence Int. 2004:35(2):143-50.

18. Glaros AG, Burton E. Parafunctional clenching, pain, and effort in temporomandibular disorders. J Behav Med. 2000;27(1):91-100.

19. Gremillion HA. The prevalence and etiology of temporomandibular disorders and orofacial pain. Tex Dent J. 2000;117(7):30-9.

20. Headache Classification Committee of The International Headache Society. Classification and diagnostic criteria for headache disorders, cranial neuralgias and facial pain. Cephalalgia. 1988;8 Suppl 7:10-73.

21. Henderson DH, Cooper JCJR, Brayan GW, Van Sickels JE. Otologic complaints in temporomandibular joint syndrome. Arch Otolaryngol Head Neck Surg. 1992;118(11):1208-13.

22. Huang GJ, Leresche L, Critchlow CW, Martin MD, Drangsholt MT. Risk factors for diagnostic subgroups of painful temporomandibular disorders (TMD). J Dent Res. 2002;84(4):284-8.

23. International Association for the Study of Pain. Classification of chronic pain: descriptors of chronic pain syndromes and definitions of pain terms. 2nd ed. Seattle: IASP Press; 1994
24. Johansson A, Unell L, Carlsson GE, Soderfeldt B, Halling A. Gender differences in symptoms related to temporomandibular disorders in a population of 50 -year-old subjects. J Orofac Pain. 2003;17(1):29-35.

25. Leresche L. Epidemiology of temporomandibular disorders: implications for the investigation of etiologic factors. Crit Rev Oral Biol Med. 1997;8(3):291-305.

26. Magnusson T, List T, Helkimo M. Self-assessment of pain and discomfort in patients with temporomandibular disorders: a comparison of five different scales with respect to their precision and sensitivity as well as their capacity to register memory of pain and discomfort. J Oral Rehabil. 1995;22(8):549-56.

27. Malkin DP. The role of TMJ dysfunction in the etiology of middle ear disease. Int Orthod. 1987;25(1-2):20-1.

28. Manfredi APS, Silva AA, Vendite LL. The sensibility appreciation of the questionnaire for selection of orofacial pain and temporomandibular disorders recommended by the American Academy of Orofacial Pain. Rev Bras Otorrinolaringol. 2001;67(6):763-8.

29. Miyake R, Ohkubo R, Takehara J, Morita M. Oral parafunctions and associations with symptoms of temporomandibular disorders in Japanese university students. J Oral Rehabil. 2004;31(6):518-23.

30. Molina OF, Santos J Jr, Mazzetto MO, Nelson SJ, Nowlin TA, Maineri ET. Oral jaw behaviors in TMD and bruxism: a comparison study by severity of bruxism. Cranio. 2001;19(2):114-22.

31. Molina OF, Santos J Jr, Nelson SJ, Grossman E. Prevalence of modalities of headaches and bruxism among patients with craniomandibular disorders. Cranio. 1997;15(4):14-25

32. Molina OF, Santos J Jr, Nelson SJ, Nowlin T. A clinical study of specific signs and symptoms of CMD in bruxers classified by the degree of severity. Cranio. 1999:17(4):268-79.

33. Morgan DH, Goode RL, Christiansen RL, Tiner LW. The TMJ-ear connection Cranio. 1995;13(1):42-3.

34. Mundt T, Mack F, Schwahn C, Benhardt O, Kocher T, John U, Biffar R. Gender differences in associations between occlusal support and signs of temporomandibular disorders: results of the population-based study of health in Pomerania (SHIP). Int J Prosthodont. 2005;18(3):232-9.

35. Nilsson IM. Reliability, validity, incidence and impact of temporomandibular pain disorders in adolescents. Swed Dent J Suppl. 2007;(183):7-86.

36. Okeson JP, Hayes DK. Long-term results of treatment for temporomandibular disorders: an evaluation by patients. J Am Dent Assoc. 1986;112(4):473-8.

37. Oliveira MF, Speciali JG. Cefaléia crônica diária: conceitos e tratamentos. Medicina. 2002;35(4):455-63.

38. Peroz I. Dysfunctions of the stomatognathic system in tinnitus patients compared to controls. HNO. 2003;51(7):544-9.

39. Rocha APF, Nardelli MR, Rodrigues MF. Epidemiologia das desordens temporomandibulares: estudo da prevalência da sintomatologia e sua interrelação com a idade e o sexo dos pacientes. Rev Serviço ATM. 2002;2(1):5-10.

40. Rosseti LM, Araújo CRP, Rosseti PH, Conti PC. Association between rhythmic masticatory muscles activity during sleep and masticatory myofascial pain: a polysomnographic study. J Orofac Pain. 2008;22(3):190-200.

41. Sato F, Kino K, Sugisaki M, Haketa T, Amemori Y, Ishikawa T, et al. Teeth contacting habit as a contributing factor to chronic pain in patients with temporomandibular disorders. J Med Dent Sci. 2006:53(2):103-9.

42. Schimitter $M$, Rammelsberg $P$, Hassel $A$. The prevalence of signs and symptoms of temporomandibular disorders in very old subjects. J Oral Rehabil. 2005;32(7):467-73.

43. Shintaku W, Enciso R, Broussard J, Clark GT. Diagnostic imaging for chronic orofacial pain, maxillofacial osseous and soft tissue pathology and temporomandibular disorders. J Calif Dent Assoc. 2006;34(8):633-44.

44. Solberg WK, Woo MW, Houston JB. Prevalence of mandibular dysfunction in young adults. J Am Dent Assoc. 1979;98(1):25-34.

45. Tartaglia GM, Silva MAM, Bottini S, Sforza C, Ferrario VF. Masticatory muscle activity during maximum voluntary clench in different research diagnostic criteria for temporomandibular disorders (RDC/TMD) groups. Manual Therapy. 2008;13(5):434-40

46. Wassell RW, Adams N, Kelly PJ. Treatment of temporomandibular disorders by stabilizing splints in general dental practice: results after initial treatment. Br Dent J. 2004;197(1):35-41.

47. Willianson EH, Hall JT, Zwemer JD. Swallowing patterns in human subjects with and without temporomandibular dysfunction. Am J Orthod Dentofacial Orthop. 1990:98(6):507-11. 